\title{
0391. Comparison of the histopathologic effects on the lungs of two external chest compression devices (lucas versus autopulse) in a swine model of ventricular fibrillation
}

\author{
C Pantazopoulos ${ }^{1 *}$, I Floros ${ }^{1}$, A Mega ${ }^{1}$, C Rigas ${ }^{1}$, I Pavleas ${ }^{1}$, P Vernikos ${ }^{1}$, N Archontoulis ${ }^{1}$, D Xanthis ${ }^{1}$, N lacovidou ${ }^{2}$, \\ T Xanthos ${ }^{3}$
}

From ESICM LIVES 2014

Barcelona, Spain. 27 September - 1 October 2014

\section{Introduction}

Given the difficulty of performing efficient CPR compressions, technology has turned to automaticity. LUCAS device has a pneumatically driven piston to compress the heart and uses active decompression suction on the upstroke. AUTOPULSE is a load distributing band compressor, that is mechanically actuated and battery driven. It provides both direct compression and semi-circumferential thoracic compression.

\section{Objectives}

Lung injury may occur during cardiorespiratory resuscitation with external chest compression devices. Aim of this study is to compare 2 different external chest compression devices (LUCAS and AUTOPULSE) regarding differences in lung injury that they may cause.

\section{Methods}

Forty (40) pigs were randomly allocated into 2 groups. Group L (LUCAS), n=20 and Group A (AUTOPULSE), $\mathrm{n}=20$. After anesthesia, ventricular fibrillation was induced. Five minutes post-cardiac arrest without treatment, resuscitation was initiated. After resuscitation, lung biopsy via a mini-thoracotomy was obtained (right lung lower lobe).

\section{Results}

Histopathology findings revealed a heterogeneous interstitial infiltrate and vascular congestion in all samples studied. There was no statistically significant difference between the two groups. $(\mathrm{P}>0.05)$

\section{Conclusions}

LUCAS and AUTOPULSE devices present no histopathological differences concerning lung injury after cardiorespiratory resuscitation.

\section{Authors' details}

'General Hospital of Athens Laiko, Intensive Care Unit, Athens, Greece. ${ }^{2}$ University of Athens, Medical School, Neonatology, Athens, Greece.

${ }^{3}$ University of Athens, Medical School, M.Sc. Programme in Cardiorespiratory Resuscitation, Athens, Greece.

Published: 26 September 2014

\section{References}

1. Axelsson C, et al: Clinical consequences of the introduction of mechanical chest compression in the EMS system for treatment of outof-hospital cardiac arrest-a pilot study. Resuscitation 2006, 71(1):47-55.

2. Ong ME, et al: Use of an automated, load-distributing band chest compression device for out-of-hospital cardiac arrest resuscitation. JAMA 2006, 295(22):2629-37.

doi:10.1186/2197-425X-2-S1-P24

Cite this article as: Pantazopoulos et al: 0391. Comparison of the histopathologic effects on the lungs of two external chest compression devices (lucas versus autopulse) in a swine model of ventricular fibrillation. Intensive Care Medicine Experimental 2014 2(Suppl 1):P24. 